\title{
ROOT CANAL IRRIGANTS AND IRRIGATION TECHNIQUES: A REVIEW
}

Aniketh T. N¹, Mohamed Idris², Geeta I. B³, Nandakishore K. J4, Gourav Kumar Sahu", Patrick Timothy Arul6 ${ }^{6}$, Jayson Mathew James ${ }^{7}$, Sahle Abdul Kareem ${ }^{8}$

\section{HOW TO CITE THIS ARTICLE:}

Aniketh T. N, Mohamed Idris, Geeta I. B, Nandakishore K. J, Gourav Kumar Sahu, Patrick Timothy Arul, Jayson Mathew James, Sahle Abdul Kareem. "Root Canal Irrigants and Irrigation Techniques: A Review". Journal of Evolution of Medical and Dental Sciences 2015; Vol. 4, Issue 27, April 02; Page: 4694-4700,

DOI: $10.14260 /$ jemds/2015/679

ABSTRACT: Root canal irrigation is not much emphasised in endodontic therapy. Most articles discussed are on root canal shaping and obturation not much emphasis is given for irrigation. There are many irrigation solutions which are introduced into market. The primary objective of root canal therapy is the retention of the pulpless or pulpally involved tooth with its associated periapical tissues in a healthy state. Achievement of this objective requires that the pulpal spaces and contents be eliminated as sources of infection. As the Enterococcus faecalis is also found to be the most important cause for endodontic failures, the action and efficacy of fewer irrigants against E. faecalis should also be given prime importance as of others. Therefore, the introduction of an antimicrobial endodontic irrigant during root canal therapy should be given priority in the hierarchy of root canal treatment. The purpose of this article is to analyse root canal irrigants, irrigation techniques and irrigation protocol.

KEYWORDS: Disinfection, EDTA, smear layer, sodium hypochlorite, root canal irrigants, Enterococcus faecalis, Endodontic irrigants.

INTRODUCTION: The aim of root canal treatment is to clean root canal by considering biological, chemical and mechanical objectives. Bacteria are the main causative factors in pulpal and periapicalpathosis. Although chemomechanical preparation of the root canals is able to reduce the number of bacteria, complete canal disinfection is difficult because of the complexity of the internal root canal anatomy. Due to the complex anatomy of the root canal system, an effective disinfection in endodontics is only achieved by augmenting mechanical preparation with antimicrobial irrigants.

Irrigation has played a main role in endodontic treatment. During and after instrumentation, the irrigantsaccomodate removal of microorganisms, dentin chips from the root canal through a flushing mechanism tissue remnants. Some irrigants also possess antimicrobial activity. Irrigants can also help prevent packing of the hard and soft tissue in the apex and extrusion of infected material into the periapical area. There is no single irrigating solution that alone sufficiently covers all of the functions required from an irrigant.

Optimal irrigation is based on the combined use of two or several irrigating solutions in a specific sequence, to predictably attain the goals of safe and effective irrigation. Complete removal of microorganisms from root canal is very important for success of treatment. Enterococcus faecalis has been only occasionally found in cases of primary endodontic infections but frequently isolated or detected in cases in which the endodontic therapy has failed. 10 In addition, to disinfectants, physical removal of cells of Enterococcus faecalis through debridement of the root canal remains essential, since remnants may sustain the inflammation. E. faecalis can be found at depths up to $300 \mu \mathrm{m}$ within dentinal tubules, where it is able to survive notwithstanding the scant available nutrients, unlike other bacterial species. 
The factors affecting irrigation are concentration of irrigant, volume of the solution, canal diameter, viscosity or surface tension of the solution, diameter and depth of penetration of the irrigating needle, contact time with the tissue, temperature of the irrigant, anatomy of the canal, method of delivering the irrigant, ultrasonic activation and the effect of combining different types of solutions.

\section{CLASSIFICATION:}

I-Chemicals Agents, II Natural Agents.

I - Chemicals Agents.

REDUCING AGENTS: Sodium hypochlorite (NAOCL).

OXIDISING AGENTS: Hydrogen peroxide (H2O2).

ANTI BATERIAL AGENTS: Chlorhexidinegluconate (CHX), MTAD, Tetraclean, smear clear, Q Mix.

CHELATING AGENTS: HEPB, EDTA, MTAD, The tracle an n, smearclear, Q-Mix.

ACIDS: Maleic acid, citric acid, poly acrylic acid, HEBP.

COMBINATIONS: MTAD, Q Mix, Tetraclean, smearclear.

OTHER NEWER IRRIGANTS: BDA solution, ruddles solution, electrochemically activated water, ozone water, salvizol, glyoxide.

II - Natural Agents - Propalis, Triphala, Meswak, Tree tea oil, Morinda Citrifolia, green tea polyphenols and Arctium Lappa.

Sodium Hypo Chlorite (NaOCL): Sodium hypochlorite has been used as an Endodontic irrigant since 1920. NaOCLis the most popular and ideal irrigating solution as it covers most of requirements as endodontic irrigant but it is caustic totissues and should be used with caution. During World War I, Chemist Henry Drysdale Dakin used 0.5\% NaOCL solution to clean infected wounds3. Various concentrations ranging from $0.5 \%$ to $5.25 \%$ have been tried out. Best regimen is reported with $5.25 \%$ for 40 minutes $41 \%-3 \%$ is ineffective against e fecalis at the same time $5 . \mathrm{NaOCl}$ is the most commonly used irrigant during endodontic therapy because of its tissue dissolving and antimicrobial properties.

Its germicidal ability is related to the formation of hypochlorous acid when in contact with bacteria and organic debris. It also has minimal "clinical toxicity" when kept within the confines of the canals. However, $\mathrm{NaOCl}$ is extremely toxic to the periapical tissues if it is injected beyond the apex of the tooth. 29 In a study conducted by Clegg et al, evaluated the effectiveness of 3 different concentrations of Naocl, $2 \%$ chx and biopure MTAD on apical dentin biofilms in vitro. He concluded that 6\% Naocl was better irrigant compared to chx and MTAD when used alone. 28 In a study done by Zohreh et al, comparison between efficacies of MTAD, Naocl, chx was done. It was concluded MTAD was far better results comparing remaining irrigants.

The Naocl can be used with few agents like namely, for better efficacy and antibacterial activity:

- Calcium hydroxide,

- EDTAC, or

- Chlorhexidine.

Hydrogen Peroxide (H202): Hydrogen peroxide (H2O2) is an irrigation solution. The mechanism of action of hydrogen peroxide (HP) involves the reaction of superoxide ions which attack lipid 
structure by producing hydroxyl ions. It also produces nascent oxygen molecules which will reduce the flushing activity on debris out of the canal and also it's cytotoxic to the periapical tissues.

Chlorhexidinedigluconate (CHX): CHX is widely used for disinfection in dentistry because of its good antimicrobial activity. It has gained considerable popularity in endodonticsas an irrigating solution and as an intra canalmedicament. CHX when mixed with Naocl it is known to produce parachloroaniline (PCA) which is found to be cytotoxic agent. CHX permeates the microbial cell wall or outer membrane and attacks the bacterial cytoplasmic or inner membrane or the yeast plasma membrane. In high concentrations, CHX causes coagulation of intracellular components. One of the reasons for the popularity of CHX is its substantivity, because CHX binds to hard tissue and remains antimicrobial. 31 In a study Harpreetsingh et al, substantivity of different concentrations of chlorhexidine in human dentin was evaluated. He concluded that $2 \%$ chlorhexidine had $81 \%$ substantivity in human dentin at 72 hours. In another study done Basrani et al, it was concluded chlorhexidine had antimicrobial activity against E. faecalis even after a period of 1week after the irrigation into the canals.

From the earlier studies, it is suggested to use chlorhexidine as a final irrigant in the irrigation protocol for better substantivity and antimicrobial effect against E. faecalis.

Chelating Agents.

It is defined as a chemical which combines with metal to form chelate.

Chelating Agents: EDTA, CITRIC ACID, POLY ACRYLIC ACID, MALEIC ACID, HEBP.

EDTA: Although sodium hypochlorite appears to be the most desirable single endodontic irrigant, it cannot dissolve inorganic dentin particles and thus prevent the formation of a smear layer during instrumentation. Demineralizing agents such as ethylenediaminetetraacetic acid (EDTA) and citric acid have therefore been recommended as adjuvants in root canal therapy. EDTA has known better biocompatibility compared to the other chelating agents also for the better activity on inorganic portion of the dentin makes it superior to all.

CITRIC ACID: It can be used alone or in combination with EDTA. Concentrations ranging from 1-40\% have been used in endodontics to remove smear layer after root canal preparation. $10 \%$ citric acid removes smear layer and has anti-microbial action 27. Citric acid should not be used with sodium hypochlorite as it interacts with $\mathrm{NaOCl}$ and reduces the available chlorine making it ineffective against microorganisms. Poly acrylic acid and 7\% malic acid may also be used to remove smear layer28. HEBP-1- Hydroxyethylidene 1, 1- bisphosphonate also known as Etidronate or etidronicacid has been suggested as an alternative to EDTA and citric acid, as it has short term reaction with NAOCL and is nontoxic to tissues. Studies have found that action of $18 \%$ of HEBP is comparatively much slower when compared with 17\% EDTA29.

MTAD: MTAD is a mixture of 3\% doxycycline, $4.25 \%$ citric acid, and detergent (tween 80 ). In MTAD the level of doxycycline is three times more than tetraclean. 15. MTAD has been reported to be effective in removing smear layer. In the MTAD preparation, the citric acid may serve to remove the smear layer, allowing doxycycline to enter the dentinal tubules and exert an antibacterial effect. 28 Newberry et al determined in vitro the antimicrobial effect of MTAD as a final irrigant on eight strains 


\section{REVIEW ARTICLE}

of E. faecalis and measured the minimum inhibitory concentration (MIC) and the minimum lethal concentration (MLC) of MTAD. After irrigating with $1.3 \% \mathrm{NaOCl}$, the root canal and the external surfaces were exposed to MTAD for five minutes. The results showed that this treatment regimen was effective in completely eliminating growth in seven of eight strains of E. faecalis.

Tetraclean: It is worth noting that it is similar to MTAD, a mixture described by Torabinejad and coworkers that is known to be effective in removing the smear layer. 33 It contains an antibiotic, an acid, and two detergents (propylene glycol and cetrimide). Tetraclean eliminates microbes that resist conventional endodontic irrigants and dressings. 34 It provides local antimicrobial activity through the affinity of doxycycline for dental tissues. 35 The two main differences between Tetraclean and MTAD, is that tetraclean contains two detergents unlike MTAD which contains single detergent (tween 80) and the level of doxycycline is three times less than MTAD. The antibacterial effectiveness of irrigants in root canal treatment may be different from the results of in vitro studies because of the dynamic biological environment with mixed bacterial cultures that usually occurs in vivo. 36

In one of the studies they compared tetralean and tetraclean in combination with Naocl. It was concluded that the tetraclean showed better antibacterial activity, but when Naocl and tetraclean was used in combination the residual antibacterial activity of tetraclean was significantly decreased in the dentin samples.

Q-MIX: A newer irrigant developed by Dr. Markus Haapasalo et al, UBC, Canada, which is recommended for final rinsing of root canal. This irrigant eradicates bacteria, removes smear layer and persists in bio films32. It contains ethylenediaminetetraacetic acid (EDTA), Chlorhexidine and cetrimide (N-Cetyl-N, N, N-Tri Mtehyl Ammonium Bromide) mixed in distilled water with acceptable additional salt.

NEWER IRRIGANTS: Electro Chemically Activated Water: Electrochemically Activated (ECA) solutions are produced from tap water and low-concentrated salt solutions. The ECA technology represents a new scientific paradigm developed by Russian scientists at the All-Russian Institute for Medical Engineering (Moscow, Russia, CIS). Principle of ECA is transferring liquids into a metastable state via an electrochemical unipolar (anode or cathode) action through the use of an element/reactor ("Flow-through Electrolytic Module" or FEM).

Advantages: Both types of ECA solutions (anolyte and catholyte) have been reported to be effective for the treatment of cutaneous and mucous infections as well as for posttraumatic and postoperative suppurative complications, and purulent surgical disease. ECA solution are recommended for use in lesion and wound irrigation or dressing. ECA solutions demonstrated more pronounced clinical effect and were associated with fewer incidences of allergic reactions compared to other antibacterial irrigants.

Ozone Water: Ozone is a chemical compound consisting of three oxygen atoms (O3-triatomic oxygen), a higher energetic form than normal atmospheric oxygen (02). Thus, the molecules of these two forms are different in structure. Ozone is produced naturally by the following natural methods. Ozone is a very powerful bactericide that can kill microorganisms effectively. It is an unstable gas, 
capable of oxidizing any biological entity. It was reported that ozone at low concentration, $0.1 \mathrm{ppm}$, is sufficient to inactivate bacterial cells including their spores. It is present naturally in air and can be easily produced by ozone generator. When introduced in water, ozone dissolves rapidly and dissociates rather quickly.

Photon: Activated Disinfection. The use of photodynamic therapy (PDT) for the inactivation of microorganisms was first shown by Oscar Raab who reported the lethal effect of acridine hydrochloride on Paramecia caudatum. PDT is based on the concept that nontoxic photosensitizers can be preferentially localized in certain tissues and subsequently activated by light of the appropriate wavelength to generate singlet oxygen and free radicals that are cytotoxic to cells of the target tissue. Methylene blue (MB) is a well-established photosensitizer that has been used in PDT for targeting various gram-positive and gram-negative oral bacteria and was previously used to study the effect of PDT on endodontic disinfection.

CONCLUSION: Irrigation and irrigation solutions have a key role in successful endodontic treatment. Many factors should be considered when choosing an irrigant for endodontic therapy which include, antimicrobial activity, effect on bonding properties, toxicity, and the ability of the irrigant to dissolve tissue. Detailed of the mode of action of various root canal irrigation solutions is important for optimal irrigation. Use of single irrigant alone does not fulfil all requirements of irrigation. There is no single irrigating solution that alone covers all the functions required from an irrigant. Recently use of combinations of irrigant, in a specific sequence has become popular as it fulfils all requirements and provides safe and effective irrigation.

\section{REFERENCES:}

1. Baumgartner JC, Falklerwa Bacteria on apical 5mm of infected root canals-. JOE1991; 17: 380-3.

2. Zehnder. M-Root canal irrigants- JOE- 2006; 32: 389-98.

3. Dakin H. D-. On the use of certain anti septics substances in treatment of wounds- Br med Jr 1915; 2; 318-20.

4. Siqueira, RocasI, Favieri. A, Lima K, Chemo mechanical reduction of bacteria population in the root canal after instrumentation and irrigation with 1\%, 2. 5\% and 5-25\% sodium hypo chlorite. Joe-2000, 26; 331-4.

5. Retamozo, Johnson N, Minimum contact time and concentration of sodium hypochlorite required to eliminate E. Fecalis. JOE2010; 36: 520-3.

6. Mcdonnell G, Russell D. Antiseptics and disinfectants: activity, action, and resistance. ClinMicrobiol Rev 1999; 12: 147-79.

7. Barrette WC Jr, Hannum DM, Wheeler WD, et al. General mechanism for the bacterial toxicity of hypochlorous acid: abolition of ATP production. Biochem J- 1989; 28: 9172-8.

8. McKenna SM, Davies KJA. The inhibition of bacterial growth by hypochlorous acid. Biochem J 1988; 254: 685-92.

9. SirtesG, WaltimoT, Schaetzle M, ZehnderM. The effect of temperatureon sodium hypo chlorite short term stability, pulp dissolution capacity and anti-microbial efficacy JOE; 31: 669-71.

10. Paragliola R, Franco V, Fabiani C. Final rinse optimization: influence of different agitation protocols. JOE 2010; 36282-5. 


\section{REVIEW ARTICLE}

11. Abou-Ross M, Oblesby SW. The effects of temperature, concentration and tissue type on the solvent ability of sodium hypo chlorite. JOE 1981; 8: 376-7.

12. Naenni. N, Thomas K, Zehnder M. Soft tissue dissolution capacity of currently used potential endodontic irrigants. JOE 2004; 30: 785-7.

13. Block S. S. (1991) Peroxygen compounds. In: Disinfection, Sterilization and Preservation. 4thEd, Philadelphia, PA, Lea-Febiger, 167-181.

14. Heling I, Chandler NP. Antimicrobial effect of irrigant combinations within dentinal tubules. IntEndod J. 1998; 31: 8-14.

15. Russell AD, Day MJ. Antibacterial activity of chlorhexidine. J Hosp Infect 1993; 25: 229-38.

16. Mohammadi. Z, Abbot PV. The properties and application of chlorhexidine in endodontics IEJ2009; 35: 583-6.

17. Siqueira JF, Paiva SS, Rocas IN. Reduction in the cultivable bacterial populations in infected root canals by chlorhexidine based anti microbialprotocol. JOE 2007, 33: 541-7.

18. Gomes BP, Ferraz C. C, Vianna ME, Berber VB, Teixeira FB, De Souza Filho FJ. In vitro antimicrobial activity of several concentrations of sodium hypochlorite and chlorhexidinegluconate in the elimination of enterococcus faecalis. IEJ2001; 34: 424-8.

19. Vianna ME, Gomes BP, Berber VB, Zaia AA, Ferraz C. C, De Souza Filho FJ. In vitro evaluation of the anti-microbial activity of chlorhexidine and sodium hypo chlorite. Oral Surg, or a l Med, or a I Pa th, Or a l Radio, Endod 2004; 97: 79-84.

20. Bösmann K. Antimicrobial efficacy chlorhexidine and two calcium hydroxide formulations against Enterococcusfaecalis. J Endod. 2005; 31 (l): 53-56.).

21. Faria G, Celes MR, De Rossi A, et al. Evaluation of chlorhexidinetoxjcity injected in the paw of mice and added to cultured L929 Hbroblasts. / Endod. 2007; 33 (6): 715-722.

22. Von Der Fehr, Nygaard Ostby B. Effect of EDTAC and Sulfuric acid on root canal dentine. Oral Surg Oral Med Oral Pathol -1963; 16: 199-205.

23. MelloI, Kammerer BA, Yoshimoto D. Influence of final rinse technique on ability of ethylene diamine tetra acetic acid of removing smear layer. JEndo-2010; 36: 512-4.

24. Kuah HG, Lui JN, Tseng PS, Chen NN-The effect of ETA with and without ultra sonics on removal of the smear layer. IEJ-2010; 43: 31-40.

25. GuXH, Mao CY, Kern M. Effect of different irrigation on smear layer removal after post space prepration. J Endo-2009; 35: 393-6.

26. Haapsalo M, Endal U, Zni H, Coil. J. Eradication of endodontic infection by instrumentation and irrigation solutions. Endodontic Topics 2005; 10: 77-102.

27. Yamaguchi M, Yoshida H, Suzuki R, Nakamura H. Root canal irrigation with citric acid solution J. Endod 1996; 22: 27-29.

28. Ballal NV, KadianS, Mala K, Bhat. KS. Comparison of the efficacy of maleic acid and EDTA in smear layer removal from instrumented human root canal-A scaningelectroninc microscopic study. J. Endod -2009; 35: 1573-6.

29. De-Deus G, Zehnder M, Reis C, Fidel RA. Longitudinal co-site optical microscopy study on the chelating ability of etidronate and EDTA using a comparative single tooth model- J. Endod2008; 34: 71-5.

30. Torabinejad M, Khademi A A, Babagoli J, Cho Y, Johnson WB, Bozhihov K et al. A new solution forthe removal of smear layer J Endod 2003; 29: 170-5. 


\section{REVIEW ARTICLE}

31. Torabinejad M, Cho. Y, Khademi A A, Shabahang S -The effect of various concentrations of sodi um hypochlorite on the ability of MTAD to remove the smear layer. J Endod- 2003; 29: 233-9.

32. M. D. Linx, Dai L et al The Effect of Q Mix, an Experimental Antibacterial Root Canal Irrigant, on Removal of Canal Wall Smear Layer and Debris - JOE-2011; 37 (1) : 80-4

33. Bakhir VM, Spector LE, Zadorozhny Yu G, Lysenko NM, Rudinsky Ya A A device for electrochemical treatment of l iquids. USSR 1989

34. Selkon JB, Babb JR, Morris R (1999) Evaluation of the antimicrobial activity of a new superoxidized water, Sterilox, for the disinfection of endoscopes. Jr of Hospital Infec- 41, 59-70.

35. Hata G, Uemura M, Weine FS, Toda T (1996) Removal of smear layer in the root canal using oxidative potential water. Journal of Endodontics 22, 643-5.

36. Nagayoshi M, Ki t amur a C, FukuizumiT, et al. Antimicrobial effect of ozonated water on bacteria invading dentinal tubules. J Endod2004; 30: 778-81.
AUTHORS:
1. Aniketh T. N.
2. Mohamed Idris
3. Geeta I. B.
4. Nandakishore K. J.
5. Gourav Kumar Sahu
6. Patrick Timothy Arul
7. Jayson Mathew James
8. Sahle Abdul Kareem

\section{PARTICULARS OF CONTRIBUTORS:}

1. Post Graduate, Department of Conservative Density \& Endodontics, Rajarajeswari Dental College \& Hospital, Bangalore.

2. Professor, Department of Conservative Density \& Endodontics, Rajarajeswari Dental College \& Hospital, Bangalore.

3. HOD, Department of Conservative Density \& Endodontics, Rajarajeswari Dental College \& Hospital, Bangalore.

4. Sr. Lecturer, Department of Conservative Density \& Endodontics, Rajarajeswari Dental College \& Hospital, Bangalore.

5. Post Graduate Student, Department of Conservative Density \& Endodontics, Rajarajeswari Dental College \& Hospital, Bangalore.

\section{FINANCIAL OR OTHER} COMPETING INTERESTS: None
6. Post Graduate Student, Department of Conservative Density \& Endodontics, Rajarajeswari Dental College \& Hospital, Bangalore.

7. Post Graduate Student, Department of Conservative Density \& Endodontics, Rajarajeswari Dental College \& Hospital, Bangalore.

8. Post Graduate Student, Department of Conservative Density \& Endodontics, Rajarajeswari Dental College \& Hospital, Bangalore.

\section{NAME ADDRESS EMAIL ID OF THE CORRESPONDING AUTHOR:}

Dr. Aniketh T. N,

Post Graduate, Department of Conservative Dentistry \& Endodontics,

Rajarajeswari Dental College \& Hospital, Bangalore.

E-mail: dranikethnaidu@gmail.com

Date of Submission: 12/03/2015. Date of Peer Review: 13/03/2015. Date of Acceptance: 20/03/2015. Date of Publishing: 02/04/2015. 